\title{
Heart rate monitoring to assess energy expenditure in children with reduced physical activity
}

Citation for published version (APA):

Berg-Emons, H. J. G., Saris, W. H. M., Westerterp, K. R., \& van Baak, M. A. (1996). Heart rate monitoring to assess energy expenditure in children with reduced physical activity. Medicine and Science in Sports and Exercise, 28(4), 496-501. https://doi.org/10.1097/00005768-199604000-00015

Document status and date:

Published: 01/01/1996

DOI:

10.1097/00005768-199604000-00015

Document Version:

Publisher's PDF, also known as Version of record

\section{Please check the document version of this publication:}

- A submitted manuscript is the version of the article upon submission and before peer-review. There can be important differences between the submitted version and the official published version of record.

People interested in the research are advised to contact the author for the final version of the publication, or visit the DOI to the publisher's website.

- The final author version and the galley proof are versions of the publication after peer review.

- The final published version features the final layout of the paper including the volume, issue and page numbers.

Link to publication

\footnotetext{
General rights rights.

- You may freely distribute the URL identifying the publication in the public portal. please follow below link for the End User Agreement:

www.umlib.nl/taverne-license

Take down policy

If you believe that this document breaches copyright please contact us at:

repository@maastrichtuniversity.nl

providing details and we will investigate your claim.
}

Copyright and moral rights for the publications made accessible in the public portal are retained by the authors and/or other copyright owners and it is a condition of accessing publications that users recognise and abide by the legal requirements associated with these

- Users may download and print one copy of any publication from the public portal for the purpose of private study or research.

- You may not further distribute the material or use it for any profit-making activity or commercial gain

If the publication is distributed under the terms of Article $25 \mathrm{fa}$ of the Dutch Copyright Act, indicated by the "Taverne" license above, 


\section{MEDICINE \& SCIENCE IN SPORTS \& EXERCISE}

LIPPINCOTT WILLIAMS \& WILKINS

(C) Williams \& Wilkins 1996. All Rights Reserved.

Volume 28(4)

April 1996

pp 496-501

Heart rate monitoring to assess energy expenditure in children with reduced physical activity [Special Communications: Methods]

VAN DEN BERG-EMONS, RITA J. G.; SARIS, WIM H. M.; WESTERTERP, KLAAS R.; VAN BAAK, MARLEEN A. Departments of Movement Sciences and Human Biology, University of Limburg, Maastricht, THE NETHERLANDS Submitted for publication December 1994.

Accepted for publication March 1995.

We wish to express our thanks to all the children and their parents who participated in this study and the staff of the children's rehabilitation center Franciscusoord (Valkenburg a/d Geul). We also thank Carola Leygraaf and Loek Wouters for their help during data collection and analysis.

Address for correspondence: Rita J. G. van den Berg-Emons, Department of Movement Sciences, University of Limburg, P.O. Box 616, 6200 MD Maastricht, The Netherlands.

Browse Table
of Contents

Outline

- $\underline{\text { ABSTRACT }}$

- $\underline{\text { SUBJECTS AND METHODS }}$

O Subjects

O Doubly Labeled Water Technique

O Heart Rate Monitoring

O Subject Calibration

- $\underline{\mathrm{RMR}}$

O Estimation of Energy Expenditure by Heart Rate Method

O Body Composition

O Statistical Analysis

- $\underline{\text { RESULTS }}$

- DISCUSSION

- $\underline{\text { REFERENCES }}$

Graphics

- Equation 5A

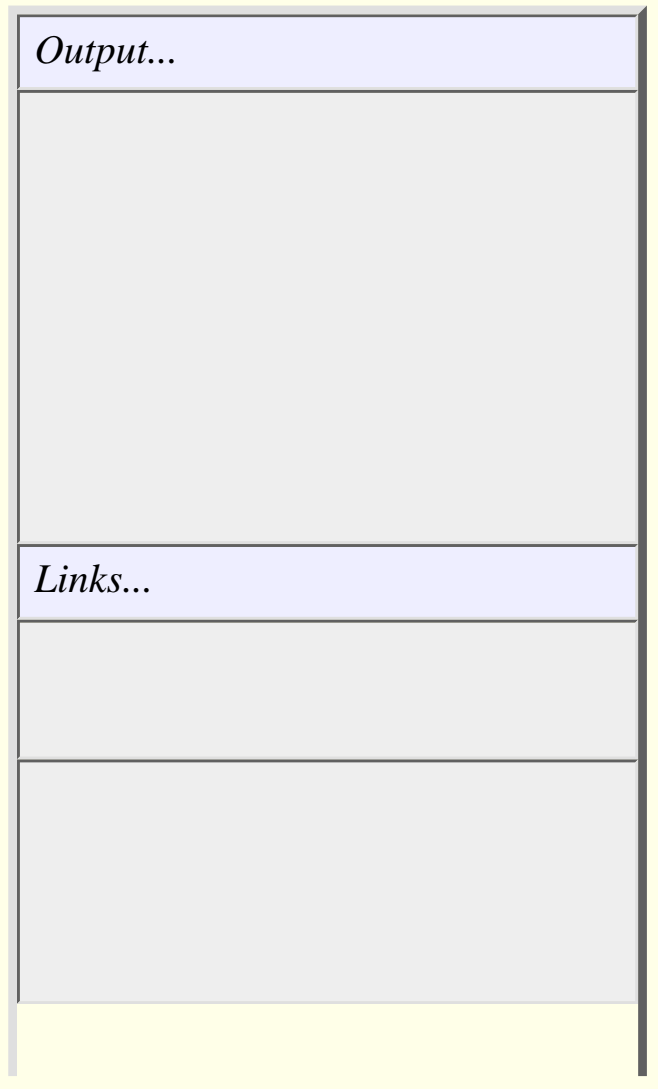


- $\underline{\text { Table } 1}$

- Table 2

- Figure 1-Difference ...

- $\underline{\text { Table } 3}$

History...

ABSTRACT

Heart rate monitoring to ...

The aim of the study was to assess whether heart rate (HR) monitoring is suitable to estimate energy expenditure in spastic cerebral palsied (CP) children, who are known to have very low levels of daily physical activity. Total daily energy expenditure (TEE) predicted from HR recording $\left(\mathrm{TEE}_{\mathrm{HR}}\right.$, measured over 2 or $3 \mathrm{~d}$ ) was therefore compared with TEE measured by doubly labeled water $\left(\mathrm{TEE}_{\mathrm{DLW}}\right.$, measured over $14 \mathrm{~d}$ ) in nine children with spastic diplegia/tetraplegia (mean $\pm \mathrm{SD}$ age $10.7 \pm 1.6 \mathrm{yr})$. At group level, there was no difference in $\mathrm{TEE}_{\mathrm{DLW}}\left(7.4 \pm 2.1 \mathrm{MJ} \cdot \mathrm{d}^{-1}\right)$ and $\mathrm{TEE}_{\mathrm{HR}}\left(7.4 \pm 2.2 \mathrm{MJ} \cdot \mathrm{d}^{-1}\right)$. Spearman correlation between both methods was $0.88(\mathrm{P}<0.001)$. Individual estimates of $\mathrm{TEE}_{\mathrm{HR}}$ ranged from- $16.9 \%$ to $+20.0 \%$, with five $\mathrm{TEE}_{\mathrm{HR}}$ values within $\pm 10 \%$ of $\mathrm{TEE}_{\mathrm{DLW}}$. It was concluded that also in children with low levels of daily physical activity, HR monitoring (preferably 3 sampling days) can provide a close group estimate of energy expenditure. At the individual level, the method is not suitable.

Physical activity is generally considered to be an important factor in the growth and development of children and adolescents (17). Also the relevance of physical activity to clinical pediatrics has been gaining increasing attention, be it in diagnosis, prevention, management, or etiology $(2)$.

Measuring daily physical activity is one of the most difficult tasks for the physiologist $(11)$ and probably even more difficult in children than in adults. A problem encountered in measuring physical activity is the presence of contradictory aims. On the one hand it is desirable to record the normal daily movements of a child, which usually means that the subject must be burdened with equipment for measuring a number of body functions. On the other hand, the child's normal daily activities should not be hindered (17).

Physical activity can be quantified by determining energy expenditure. At the moment, the doubly labeled water (DLW) technique seems to be the most accurate low-interference technique for measuring total daily energy expenditure (TEE). However, for large-scale application the method is limited because of its cost. Furthermore, the technique provides only an overall estimate of energy expenditure for the entire observation period (17).

Heart rate (HR) monitoring is a simple and inexpensive method with little inconvenience to the subject, especially with the new developments in microelectronics. Therefore, HR monitoring has become one of the most commonly employed methods in physical activity studies in children (17). There are, however, certain disadvantages in using this method of prediction: the relationship between $\mathrm{HR}$ and oxygen consumption $\left(\cdot \mathrm{VO}_{2}\right)$ is dependent upon the type of exercise $\underline{(8)}$; and, furthermore, the method is less accurate at low levels of physical activity because of the influence of several factors(emotional stress, posture) on the HR- $\cdot \mathrm{VO}_{2}$ relation $(4,7)$. Disadvantages of the HR method have been established in adults with metabolic disorders $(7)$, healthy adults $\underline{(4-6,8,14,21,22,24)}$, and healthy children $\underline{(9,15)}$.

Children with spastic cerebral palsy (CP) have very low levels of daily physical activity (3). Therefore, it might be hypothesized that the HR method is unsuitable to predict energy expenditure in these children. The aim of the present study was to compare HR monitoring with the DLW technique for the measurement of TEE in children with spastic CP. As far as we know, no studies exist concerning the validity of HR monitoring to predict energy expenditure in a group of subjects with such low levels of daily physical activity, as children with spastic CP are known to have.

SUBJECTS AND METHODS 
Subjects

Nine children with $\mathrm{CP}(5$ boys and 4 girls), spastic diplegia $(\mathrm{N}=6)$ or spastic tetraplegia $(\mathrm{N}=3)$, volunteered to participate as subjects. All children were between 8 and $13 \mathrm{yr}$ of age and were day students at the children's rehabilitation center Franciscusoord in Valkenburg (normal intelligence and mild mental retardation). Three children were ambulant and six were wheelchair-bound. All children were Caucasian and participated in a 9-month sports program with 45-min aerobic exercise sessions (cycling, wheelchair-driving, running) two times per week. The children and their parents were informed of all aspects of the study, and written consent was obtained. The study was approved by the Medical Ethics Committees of the University of Limburg and the Cooperating Rehabilitation Centers Limburg.

Doubly Labeled Water Technique

TEE was measured using the doubly labeled water technique $\left(\mathrm{TEE}_{\mathrm{DLW}}\right)$. This technique measures TEE over longer periods of time by assessing the difference in disappearance rates of two stable isotopes, ${ }^{18} \mathrm{O}$ and $^{2} \mathrm{H} \underline{(13)}$. Measurements were performed in the spring from April to June, during a normal school period. Individually calculated doses of ${ }^{2} \mathrm{H}_{2}{ }^{18} \mathrm{O}$, which were expected to create an excess of about $300 \mathrm{ppm}{ }^{18} \mathrm{O}$ and $150 \mathrm{ppm}^{2} \mathrm{H}$ in the body water, were administered orally to the children in the evening of day 0, after collecting a baseline urine sample. To avoid spillage of isotope due to oral motor problems, a straw was used and children were asked to drink the water slowly. After emptying the dosage bottle, it was rinsed with $50 \mathrm{ml}$ of tap water, which was consumed through the same straw. In none of the children was loss of isotope observed. Further urine samples were collected on days 1, 8, and 15 in the morning after the first voiding and before going to bed at night. Isotope abundances in the urine samples were measured with an isotope ratio mass spectrometer (Aqua Sira, VG Isogas, Middlewich, Cheshire, England). The ${ }^{18} \mathrm{O}$ analyses were reproducible within $0.4 \mathrm{ppm}$ and ${ }^{2} \mathrm{H}$ within $0.2 \mathrm{ppm}$. Excesses of ${ }^{18} \mathrm{O}$ and ${ }^{2} \mathrm{H}$ ranged from 282 to $388 \mathrm{ppm}$ and from 136 to $178 \mathrm{ppm}$, respectively. Mean TEE ${ }_{\mathrm{DLW}}$ over $14 \mathrm{~d}$ was calculated using an estimated fixed respiratory quotient (RQ) of 0.85 and the equation (20): Equation

Graphic

[Help with image viewing]

Equation 5A

[Email Jumpstart To Image]

where $\mathrm{rCO}_{2}=\mathrm{CO}_{2}$ production rate $\left(\right.$ mol.d $\left.\mathrm{d}^{-1}\right), \mathrm{N}=$ total body water $(\mathrm{mol}) ; \mathrm{k}_{\mathrm{o}}=$ elimination rate ${ }^{18} \mathrm{O} ; \mathrm{k}_{\mathrm{H}}=$ elimination rate ${ }^{2} \mathrm{H}$; $\mathrm{r}_{\mathrm{Gf}}=$ correction factor for evaporative water loss, estimated by formula $\mathrm{r}_{\mathrm{Gf}}=1.05 \mathrm{~N}\left(\mathrm{~K}_{\mathrm{o}}-\mathrm{k}_{\mathrm{H}}\right)$.

Heart Rate Monitoring

HR was monitored during the isotope-measurement period with a Sport Tester or Sport Tester PE3000 (Polar Electro, Kempele, Finland). The HR transmitter was attached to the chest with two disposable pregelled electrodes or if possible with an electrode belt. Plasters were used to consolidate the attachment. The receiver was worn on the wrist, with the function keys masked. Pulse was recorded at 1-min intervals. Data were retrieved via an interface unit and microcomputer.

Sampling days included two school days (one with physical training during school time and one without) and one weekend day. Heart rate was measured during waking hours; energy expenditure at night was assumed to be equal to resting metabolic rate (RMR). Because of malfunction of some HR recorders, a number of measurements was too short to estimate energy expenditure from HR. However, all children had >=2 d of complete HR recordings and four subjects completed $3 \mathrm{~d}$.

Subject Calibration

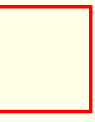

Each subject was individually calibrated under standardized conditions to establish the relation between $\mathrm{HR}$ and $\cdot \mathrm{V}_{2}$. In the ambulant children, four calibration points were obtained by simultaneous measurements of $\mathrm{HR}$ and $\cdot \mathrm{VO}_{2}$ during sitting, standing, and cycling on a mechanically braked ergometer (Universal Ergostat Fleisch, Metabo, Epalinges, Switzerland) at 
$30 \%$ and at $70 \%$ of their previously determined peak aerobic capacity. $\cdot \mathrm{VO}_{2}$ was measured using a face mask connected to a Jaeger EOS-sprint analyzer (Jaeger Nederland, Breda, The Netherlands) and heart rates were taken from an ECG monitor. A preliminary equilibration period of 2 min was allowed for each activity, followed by a 4-min sampling period. The calibration point for each activity was computed as the mean of the 4-min sampling period of the $\mathrm{HR}$ and $\cdot \mathrm{VO}_{2}$. For the children in wheelchairs, two calibration points were obtained: during sitting and during arm cranking. Arm cranking tests were performed on the Fleisch ergometer with one arm, while the children were sitting in their own wheelchair beside the ergometer. It turned out to be impossible to perform $\cdot \mathrm{VO}_{2}$ measurements while cranking with two arms, because when sitting behind the ergometer, the distance between cranks and face was so small that the cranks constantly hit the tube that connected the mask with the analyzer. Children performed the arm cranking tests at about $30 \%$ of their peak aerobic capacity for work with two arms. It was impossible to measure $\mathrm{HR}$ and $\cdot \mathrm{VO}_{2}$ at higher intensities, because when the resistance was increased, the children lowered their cranking speed and showed no increase in $\mathrm{HR}$ and $\cdot \mathrm{VO}_{2}$.

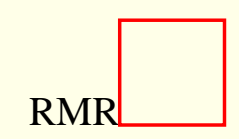

In all the subjects, RMR was determined under standard conditions in a comfortably warm room by an open-circuit ventilated hood system (Oxycon Beta, Mijnhardt, The Netherlands). The children arrived by car at the university between 7:30 and 8:15 a.m., having fasted for $12 \mathrm{~h}$. They were transported to the ventilated hood room in wheelchairs. After a period of 5-min bed rest, RMR was measured during 20 min while the children were watching TV or listening to stories (supine position). RMR was calculated according to the formula of Weir $\underline{(25)}$.

Estimation of Energy Expenditure by Heart Rate Method

TEE was calculated from HR ( $\left.\mathrm{TEE}_{\mathrm{HR}}\right)$ using a modification of the method of Saris et al. (18), as was validated by Spurr et al. (22). This requires the definition of a"FLEX" HR for each subject, above which there is a strong relation between HR and $\cdot \mathrm{VO}_{2}$, and below which the two variables are rather poorly correlated.

In the present study, FLEX HR in the ambulant children was defined as the mean of the highest HR for the standing activity and the lowest HR of the exercise activities. Energy expenditure during rest was calculated as the mean $\cdot \mathrm{VO}_{2}$ of lying (ventilated hood), sitting, and standing. Energy expenditure for periods of the daytime when the HR was <= FLEX HR, was calculated on basis of this mean $\cdot \mathrm{VO}_{2}$. When $\mathrm{HR}$ was above FLEX HR, energy expenditure was derived from the minute-by-minute recorded HR and the subject's calibration curve obtained on the bicycle. In the wheelchair-bound children, FLEX HR was defined as the mean HR for sitting. For periods of the daytime when the HR was <= FLEX HR, energy expenditure was calculated on basis of the mean $\cdot \mathrm{VO}_{2}$ of lying (ventilated hood) and sitting; when the HR was above the FLEX HR, energy expenditure was calculated from the HR recordings and the individual calibration curves obtained from HR and $\cdot \mathrm{VO}_{2}$ measurements during sitting and arm cranking. $\mathrm{TEE}_{\mathrm{HR}}$ was computed by summing the estimated energy expenditure from HR (using an energy equivalent of $20.50 \mathrm{~kJ} \cdot 1^{-1}$ ) and adding energy expenditure at night (=RMR).

Body Composition

Body mass and total body water (TBW) were measured at the start of the experimental period and redetermined at the end.

Body mass was obtained with an electronic balance (August Sauter GmbH, Albstadt, Germany) in the mornings of day 1 and day 16, before subjects consumed any food/drink and while wearing underclothing. Children who were unable to stand upright were measured while sitting on a chair, using the same balance.

At the start of the experimental period, TBW was assessed by analyzing the urine samples collected on the evening of day 0 (baseline sample) and on the morning of day 1 after the first voiding. At the end of the experimental period, i.e., before going to bed at night on day 15 , a ${ }^{2} \mathrm{H}_{2} \mathrm{O}$ (deuterium) dilution was orally administered to the children, after emptying the bladder (baseline urine sample). The dosage was expected to create an excess of $100 \mathrm{ppm}^{2} \mathrm{H}$. A second urine sample was collected on day 16 in the morning, after the first voiding. TBW from deuterium dilution was calculated as the deuterium dilution space divided by 1.04, to account for the overestimate of TBW due to proton exchange that occurs between the tracer and nonaqueous hydrogen of body solids (12). Percentage body fat was calculated from TBW, assuming that water is $75 \%$ (boys) 
Ovid: VAN DEN BERG EMONS: Med Sci Sports Exerc, Volume 28(4).April 1996.496-501

and $76 \%$ (girls) of the fat-free mass (FFM) $\underline{(10)}$.

Height measurement were taken once during the experimental period. Subjects were measured while standing against a wall, or if unable to stand independently, while lying on a bed with a wooden T-square or a flexible tape. Physical characteristics of the subjects are presented in Table 1.

Graphic

[Help with image viewing]

TABLE 1. Characteristics of the nine children with cerebral palsy.

[Email Jumpstart To Image]

Statistical Analysis

Comparisons between data were made using the Wilcoxon test for paired observations ([alpha] $=0.05)$. Agreement between methods was assessed with the method of Altman and Bland (1). Dispersion between HR sampling days was expressed as the coefficient of variation $(\mathrm{CV})$. Bivariate correlations were performed by Spearman's rank order correlation $\left(\mathrm{r}_{\mathrm{S}}\right)$.

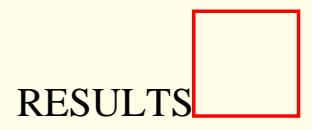

Individual results of the HR monitoring and the DLW method are presented in Table 2. Four children completed $3 \mathrm{~d}$ (1 weekend day and 2 school days) of HR recording; four children completed only two school days and one child had one complete school day and one weekend day. Because the $\mathrm{CV}$ in $\mathrm{TEE}_{\mathrm{HR}}$ between the sampling days was relatively small (5\%, mean $\mathrm{TEE}_{\mathrm{HR}}=7.1 \mathrm{MJ} \cdot \mathrm{d}^{-1}$, pooled $\mathrm{SD}=0.35 \mathrm{MJ} \cdot \mathrm{d}^{-1}$ ), the average (unweighted) $\mathrm{TEE}_{\mathrm{HR}}$ of the sampling days was used for

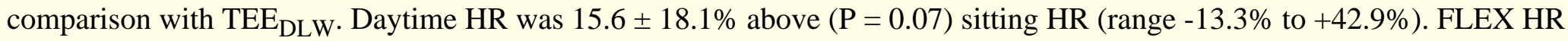
was on average $4.0 \pm 12.9 \%$ lower (NS) than daytime HR (range $-27.6 \%$ to $+15.3 \%$ ). On average, the children spent $54.1 \pm$ $32.0 \%$ of the daytime at HR > FLEX HR. There was no significant correlation between percentage of time spent above FLEX HR and the discrepancy between HR monitoring and the DLW method, nor between level of daily physical activity (calculated as $\mathrm{TEE}_{\mathrm{DLW}} / \mathrm{RMR}$ ) and the discrepancy between the methods. At group level, there was no difference in $\mathrm{TEE}_{\mathrm{DLW}}$ and $\mathrm{TEE}_{\mathrm{HR}}$. Spearman correlation between both methods was $0.88(\mathrm{P}<0.001)$. Individual estimates of $\mathrm{TEE}_{\mathrm{HR}}$ ranged from $-16.9 \%$ to $+20.0 \%\left(-2.1 \mathrm{MJ} \cdot \mathrm{d}^{-1}\right.$ to $\left.+1.8 \mathrm{MJ} \cdot \mathrm{d}^{-1}\right)$, with $5(=56 \%) \mathrm{TEE}_{\mathrm{HR}}$ values lying within $\pm 10 \%$ of $\mathrm{TEE}_{\mathrm{DLW}}$.

Intra-individual differences between the methods were larger $(\mathrm{P}=0.05)$ in the children with two sampling days $(13.5 \pm 6.3 \%)$ than in the children with three sampling days $(5.9 \pm 5.8 \%)$. In six children, $\mathrm{TEE}_{\mathrm{HR}}$ was lower than corresponding $\mathrm{TEE}_{\mathrm{DLW}}$. There was no statistically significant difference in $\mathrm{TEE}_{\mathrm{HR}}$ of the school day with a training session and the school day without training $(\mathrm{N}=8)$. Spearman correlation between $\mathrm{TEE}_{\mathrm{HR}}$ of the two school days was $0.98(\mathrm{P}<0.001)$. There was also no significant difference in $\mathrm{TEE}_{\mathrm{HR}}$ of the school days and the weekend day, but this comparison could only be made in five children.

Graphic

[Help with image viewing]

[Email Jumpstart To Image]
TABLE 2. Total energy expenditure estimated from heart rate $(\mathrm{HR})$ monitoring $\left(\mathrm{TEE}_{\mathrm{HR}}\right)$ and from doubly labeled water $\left(\mathrm{TEE}_{\mathrm{DLW}}\right)$ in nine children with cerebral palsy.

In Figure 1, the difference in TEE between HR monitoring and the DLW method is plotted against the average measurement according to Altman and Bland (1). There was no significant relation between the difference and the average.

Graphic

[Help with image viewing] [Email Jumpstart To Image]
Figure 1-Difference in total daily energy expenditure (TEE) determined by the doubly labeled water method (TEEDLW) and heart rate monitoring (TEEHR) versus average TEE. 


\section{DISCUSSION}

To assess whether HR monitoring is suitable to estimate energy expenditure in children with very low levels of daily physical activity, TEE predicted from HR was compared with TEE measured by DLW in nine children with spastic CP.

The ratio of $\mathrm{TEE}_{\mathrm{DLW}}$ to $\mathrm{RMR}$ (=index for the level of daily physical activity) in the children with $\mathrm{CP}$ was $1.28 \pm 0.22$ (Table 2). Although different methods were used to assess physical activity, comparison with studies in healthy children indicates that the children with CP are considerably less active than healthy children(activity levels in healthy children in The Netherlands (3) and Northern Ireland (15) were found to be, respectively, $1.83 \pm 0.23$ and $1.77 \pm 0.21$ ). The low physical activity in the children with $\mathrm{CP}$ is in agreement with our previous study in children with diplegic CP (3).

The DLW method has been validated in adults $\underline{(16)}$ and infants $\underline{(26)}$ and is considered to be the gold standard for measurements of energy expenditure. Using a fixed RQ for the calculation of energy expenditure over longer periods of time, has been shown to produce minimal error (error in estimation is 1\% for each unit RQ)(19). The Sport Tester PE3000 has been validated against ECG heart rates in children in laboratory and field settings $\underline{(23)}$. It was concluded that the device provides valid readings of children's HR across a wide range of exercise involving upper- and lower-body movements.

Because of earlier measurements, the children of the present study were familiar with the calibration procedure. Therefore, the calibration was not an event of high excitement for them. In spite of this, two children (Table 2, numbers 12 and 15) had a high HR during sitting(was even higher than daytime HR), probably still due to emotional stress during the calibration.

In the ambulant children the calibration activity for the active part of the HR-curve was cycling. No significant difference was found in the $\mathrm{HR}-\cdot \mathrm{VO}_{2}$ relationship between walking on a treadmill and cycling in six ambulant children with $\mathrm{CP}$ (including the ambulant children of the present study) measured in our laboratory.

The low $\mathrm{TEE}_{\mathrm{DLW}}$ to RMR ratio in the CP group (1.28 \pm 0.22 , Table 2) seems to be in contrast with the mean HR during daytime (101 bts.min $\left.{ }^{-1}\right)$ and the percentage of the daytime spent at HR > FLEX HR (54.1\%): in healthy, more active children (physical activity index $=1.77 \pm 0.21$ ) in Northern Ireland $\underline{(15)}$, mean daytime HR and percentage of daytime spent at HR > FLEX HR were, respectively, 104 beats $\mathrm{min}^{-1}$ and $41.3 \%$. However, both studies cannot be compared properly because the slopes of the regression lines between $\mathrm{HR}$ and $\cdot \mathrm{VO}_{2}$ may differ between $\mathrm{CP}$ and healthy children and the definition of the FLEX HR differs between the studies.

The $\mathrm{TEE}_{\mathrm{DLW}}$ to RMR ratios in two children with $\mathrm{CP}$ (numbers 11 and 15, Table 2) were extremely low. These children were severely affected, but the measured ratio in these children may be an underestimation of their actual ratio. Possibly, these children were not fully "at rest" during the RMR measurement.

Because of the low levels of daily physical activity in children with $\mathrm{CP}$, it is to be expected that the HR method is less suitable in these children than in healthy children with relatively high activity levels or adults with intermediate levels. The limited number of calibration activities at different intensities that are possible in severely affected wheelchair-bound children and the fact that, for practical reasons, no calibration points could be obtained for wheelchair-driving and arm cranking had to be performed with one arm, might further decrease the accuracy of the HR method in children with CP.

However, the results of the present study do not confirm this hypothesis. At group level, HR monitoring resulted in a good prediction of TEE. Individual $\mathrm{TEE}_{\mathrm{HR}}$ and $\mathrm{TEE}_{\mathrm{DLW}}$ discrepancies ranged from $-16.9 \%$ to $+20.0 \%$, but are similar to discrepancies found in healthy children and adults (Table 3). Apparently, the low activity level in children with CP and the limitations in calibration activities do not result in poorer accuracy of the HR method in children with $\mathrm{CP}$ than in healthy subjects. No significant correlation was found between percentage of time spent at HR > FLEX HR or TEE $\mathrm{DLW}_{\text {to RMR ratio }}$ and the discrepancy between $\mathrm{TEE}_{\mathrm{HR}}$ and $\mathrm{TEE}_{\mathrm{DLW}}$. This may be due to the small number of subjects. However, from the studies presented in Table 3, also no tendency can be seen that the level of physical activity is a limiting factor in the accuracy of predicting TEE from HR.

TABLE 3. Validation studies (using doubly labeled water (DLW) or indirect calorimetry (CAL) as reference method) of heart 
Ovid: VAN DEN BERG EMONS: Med Sci Sports Exerc, Volume 28(4).April 1996.496-501

Graphic

rate monitoring for the estimation of total daily energy expenditure (TEE) in healthy subjects.

[Help with image viewing]

[Email Jumpstart To Image]

Saris (17) suggested that one of the inaccuracies of the minute-by-minute HR method might be due to a slower return of HR to resting levels than the return of $\cdot \mathrm{VO}_{2}$ after bouts of activity. It may be possible that the relatively few bouts of activity in children with $\mathrm{CP}$, compensate for the possibly decreased accuracy of the HR method due to low activity levels and limitations in calibration activities in this group.

In conclusion, results of the present study indicate that the HR method can provide a close group estimate of energy expenditure in children with spastic CP with extremely low levels of daily physical activity (preferably 3 sampling days). Apparently, in contrast with what was expected, low physical activity does not necessarily result in poor accuracy of the HR method. The method is limited in the prediction of energy expenditure in individuals, but in comparison with the expensive DLW method, HR monitoring seems to be the most suitable method in large-scale activity studies to predict energy expenditure for groups with reduced physical activity (for example in rehabilitation research).

REFERENCES

1. Altman, D. G. and J. M. Bland. Measurement in medicine: the analysis of method comparison studies. The Statistician 32:307-317, 1983. [Context Link]

2. Bar-Or, O. Pediatric Sports Medicine for the Practitioner: From Physiologic Principles to Clinical Applications. New York: Springer Verlag, 1983, pp. xix-xxi. [Context Link]

3. Berg-Emons, Van Den, H. J. G, W. H. M. Saris, D. C. De Barbanson, K. R. Westerterp, A. Huson, and M. A. Van Baak. Daily physical activity of school children with spastic diplegia and of healthy control subjects. J. Pediatr. 127:578-584, 1995. [Context Link]

4. Booyens, J. and G. R. Hervey. The pulse rate as a means of measuring metabolic rate in man. Can J. Biochem. Physiol. 38:1301-1309, 1960. [Context Link]

5. Bradfield, R. B., P. B. Huntzicker, and G. J. Fruehan. Simultaneous comparison of respirometer and heart-rate telemetry techniques as measures of human energy expenditure. Am. J. Clin. Nutr. 6:696-700, 1969. Bibliographic Links [Context Link]

6. Ceesay, S. M., A. M. Prentice, K. C. Day, et al. The use of heart rate monitoring in the estimation of energy expenditure: a validation study using indirect whole-body calorimetry. Br. J. Nutr. 61:175-186, 1989. Bibliographic Links [Context Link]

7. Christensen, C. C., H. M. M. Frey, E. Foenstelien, E. Aadland, and H. E. Refsum. A critical evaluation of energy expenditure estimates based on individual $\mathrm{O}_{2}$ consumption/heart rate curves and average daily heart rate. Am. J. Clin. Nutr. 37:468-472, 1983. Bibliographic Links [Context Link]

8. Dauncey, M. J. and W. P. T. James. Assessment of the heart-rate method for determining energy expenditure in man, using a wholebody calorimeter. Br. J. Nutr. 42:1-13, 1979. Bibliographic Links [Context Link]

9. Emons, H. J. G., D. C. Groenenboom, K. R. Westerterp, and W. H. M. Saris. Comparison of heart rate monitoring combined with indirect calorimetry and the doubly labelled water $\left({ }^{2} \mathrm{H}_{2}{ }^{18} \mathrm{O}\right)$ method for the measurement of energy expenditure in children. Eur. J. Appl. Physiol. 65:99-103, 1992. Bibliographic Links [Context Link]

10. Fomon, S. J., F. Hascke, E. E. Ziegler, and S. E. Nelson. Body composition of reference children from birth to age 10 years.Am. J. Clin. Nutr. 35:1169-1175, 1982. [Context Link]

11. Garrow, J. R. Energy Balance and Obesity in Man. Amsterdam: Elsevier/North-Holland Publishers, 1974, pp. 47-92. [Context Link]

12. Haggarty, P., B. A. McGaw, M. F. Fuller, S. L. Christie, and W. W. Wong. Water hydrogen incorporation into body fat in pigs: effect on double-triple-labeled water method. Am. J. Physiol. 260:R629-R634, 1991. [Context Link] 
13. Lifson, N. and R. McClintock. Theory of use of the turnover rates of body water for measuring energy balance and material balance. J. Theor. Biol. 12:46-74, 1966. Bibliographic Links [Context Link]

14. Livingstone, M. B. E., A. M. Prentice, W. A. Coward, et al. Simultaneous measurement of free-living energy expenditure by the doubly labeled water method and heart-rate monitoring. Am. J. Clin. Nutr. 52:59-65, 1990. Bibliographic Links [Context Link]

15. Livingstone, M. B. E., W. A. Coward, A. M. Prentice, et al. Daily energy expenditure in free-living children: comparison of heart-rate monitoring with the doubly labeled water $\left({ }^{2} \mathrm{H}_{2}{ }^{18} \mathrm{O}\right)$ method.Am. J. Clin. Nutr.. 56:343-352, 1992. Bibliographic

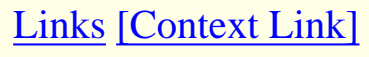

16. Prentice, A. M. (Ed.). The doubly labeled water method for measuring energy expenditure, technical recommendations for use in humans. A consensus report by the IDECG working group. Vienna: International Atomic Energy Agency, 1990, pp. 1-12. [Context Link]

17. Saris, W. H. M. Habitual physical activity in children: methodology and findings in health and disease. Med. Sci. Sports Exerc. 18:253-263, 1986. Bibliographic Links [Context Link]

18. Saris, W. H. M., I. Boeijen, H. Elvers, T. De Boo, and R. A. Binkhorst. Determining the individual variation in energy metabolism in 8-year-old children by two prediction methods. Nutr. Rep. Int. 26:35-42, 1982. Bibliographic Links [Context $\underline{\text { Link] }}$

19. Schoeller, D. A. Energy expenditure from doubly labeled water: some fundamental considerations in humans. Am. J. Clin. Nutr. 38:999-1005, 1983. Bibliographic Links [Context Link]

20. Schoeller, D. A., E. Ravussin, Y. Schutz, K. J. Acheson, P. Baertschi, and E. Jequier. Energy expenditure by doubly labeled water: validation in humans and proposed calculation. Am. J. Physiol. 250:R823-R830, 1986. Bibliographic Links [Context Link]

21. Schulz, S., K. R. Westerterp, and K. Bruck. Comparison of energy expenditure by the doubly labeled water technique with energy intake, heart rate, and activity recording in man. Am. J. Clin. Nutr. 49:1146-1154, 1989. Bibliographic Links [Context $\underline{\text { Link] }}$

22. Spurr, G. B., A. M. Prentice, P. R. Murgatroyd, G. R. Goldberg, J. C. Reina, and N. T. Christman. Energy expenditure from minute-by-minute heart-rate recording: comparison with indirect calorimetry.Am. J. Clin. Nutr. 48:552-559, 1988. Bibliographic Links [Context Link]

23. Treiber, F. A., L. Musante, S. Hartdagan, H. Davis, M. Levy, and W. B. Strong. Validation of a heart rate monitor with children in laboratory and field settings. Med. Sci. Sports Exerc. 21:338-342, 1989. [Context Link]

24. Washburn, R. A. and H. J. Montoye. Validity of heart rate as a measure of mean daily energy expenditure. Exerc. Physiol. 2:161-172, 1986. [Context Link]

25. Weir, J. B. New methods for calculating metabolic rate with special reference to protein metabolism. J. Physiol. 109:1-9, 1949. [Context Link]

26. Westerterp, K. R., H. N. Lafeber, E. J. Sulkers, and P. J. J. Sauer. Comparison of short term indirect calorimetry and doubly labeled water method for the assess ment of energy expenditure in preterm infants.Biol. Neonat. 60:75-82, 1991. [Context Link]

ENERGY EXPENDITURE; HEART RATE MONITORING 